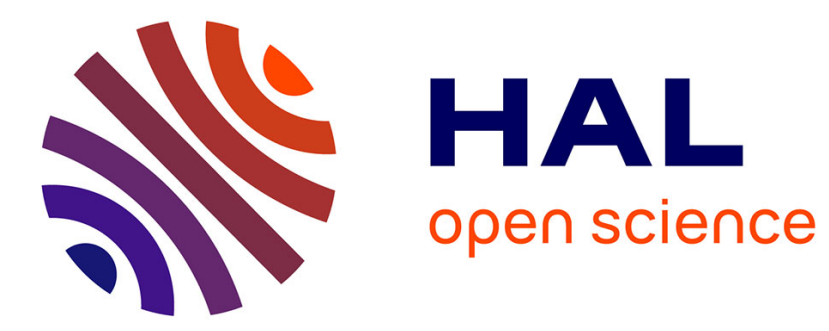

\title{
A topological approach for human movement classification and anticipation
}

Chakib Arslane Bensekka, Christophe Guillet, Frederic Merienne, Thierry Pozzo

\section{- To cite this version:}

Chakib Arslane Bensekka, Christophe Guillet, Frederic Merienne, Thierry Pozzo. A topological approach for human movement classification and anticipation. Gait \& Posture, 2017, 57, supplément 1, pp.229-230. 10.1016/j.gaitpost.2017.06.387 . hal-01588554

\section{HAL Id: hal-01588554 \\ https://u-bourgogne.hal.science/hal-01588554}

Submitted on 9 Mar 2018

HAL is a multi-disciplinary open access archive for the deposit and dissemination of scientific research documents, whether they are published or not. The documents may come from teaching and research institutions in France or abroad, or from public or private research centers.
L'archive ouverte pluridisciplinaire HAL, est destinée au dépôt et à la diffusion de documents scientifiques de niveau recherche, publiés ou non, émanant des établissements d'enseignement et de recherche français ou étrangers, des laboratoires publics ou privés. 


\title{
A topological approach for human movement classification and anticipation
}

\author{
Chakib Arslane Bensekka ${ }^{a, *}$, Christophe Guillet ${ }^{\mathrm{b}}$, Frederic Merienne $^{\mathrm{a}}$, Thierry Pozzo ${ }^{\mathrm{c}}$ \\ a LE2I FRE 2005, Arts et Métiers, CNRS, Univ. Bourgogne Franche-Comté, HeSam, Institut Image, Chalon-sur-Saône, France \\ b LE2I FRE 2005, ,CNRS, Arts et Métiers, Univ. Bourgogne Franche-Comté, Chalon-sur-Saône, France \\ ${ }^{\mathrm{c}}$ Institut National de Santé et de Recherche Médicale (INSERM U1093), Cognition Action et Plasticité Sensorimotrice (CAPS) UMR1093, Dijon, France
}

\section{Introduction}

The motion capture systems are increasingly used for biomedical purposes. In order to recognize and classify the movements, however whole-body movements using passive markers, generate a huge amount of data. Several works have been realized, with the main idea of using kinematic data as input for independent component analysis (ICA), or machine learning algorithms [1]. These approaches return high accuracy, but remain very sensitive to the noise and to the impact of the morphological difference between subjects. In contrast, we propose to apply a topological data analysis method, based on persistent homology [2], which captures essential features of data in a robust manner [3] that avoids these limitations, before to perform classification using machine-learning methods.

\section{Research question}

Can topological data analysis methods improve the recognition of movements? Can we use the results of this analysis combined with particular types of neural networks to anticipate the continuation of a movement?

\section{Methods}

With motion capture systems, the movement is defined as a sequence of postures. Thus, we record a sequence of $\mathrm{N}$ postures. The main idea of our work is to apply a topological analysis method on the 3D coordinates of the markers at each posture, in order to define a topological signature called persistent diagram [2]. Thus for a movement with $\mathrm{N}$ postures, we obtain $\mathrm{N}$ topological signatures, one for each posture. Once the topological analysis is carried out, distances between topological signatures can be obtained using a metric like Wasserstein or Bottleneck distance as described in [4]. We obtain an $\mathrm{N} \times \mathrm{N}$ distance matrix, which contains pairwise distances between each posture and the others for a same movement. We then reduce the dimension of matrix, using dimensional reduction method like MDS or Isomap, which generates point cloud, representing the distribution of topological signatures that we use as input for neural networks. In second time, we use recurrent neural network to anticipate the movements.

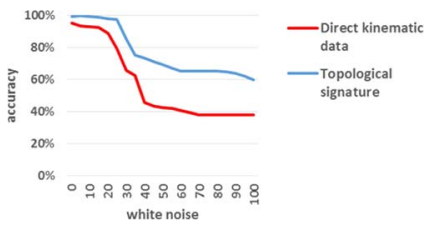

Fig. 1. Robustness test of the both approaches (The impact of white noise)

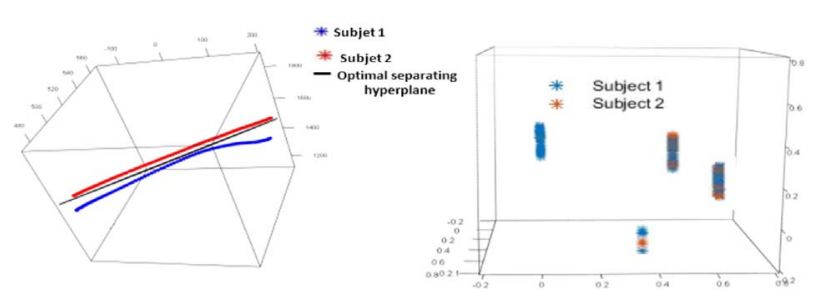

Fig. 2. Intra-movement classification, using SVM on kinematic data (left), and using the topological approach (right) with overlapping distributions of topological signatures.

\section{Results}

For the inter-motion classification, with either kinematic data or topological signatures, we obtain a high accuracy $\cong 99 \%$ (Fig. 1). But the use of kinematic data directly for intra-movement classification is impacted by the morphological difference between subjects, contrary to the topological approach (Fig. 2). For the robustness test, with the addition of a white noise spanning the range $[10 \mathrm{~mm} ; 100 \mathrm{~mm}]$, we lose more quickly the accuracy of the classical method using kinematic data, with a decreasing accuracy from $99 \%$ to $40 \%$. With the topological approach, we lose less quickly precision which stays around $60 \%$ even at $100 \mathrm{~mm}$ of noise (Fig. 1). Finally, we use a sample of the topological signatures, which represents $\cong 15 \%$ of the whole recording as an input for an Elman neural network (Fig. 3). We obtain $\cong 90 \%$ of anticipation accuracy. 


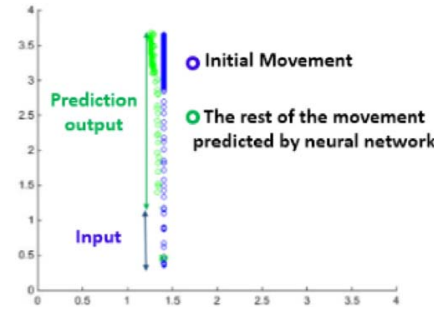

Fig. 3. Predict the continuation of the movement, with Elman recurrent neural network.

\section{Discussion}

The reults show that the addition of a topological analysis step in a movement data analysis process, based on the persistent homology before the classification, improve dealing with noise issue and morphological difference between subjects, for the intra-movement comparison. An advantage of the topological analysis method of movement is its ability to be combined with a recurrent neural network to anticipate movements. More than physical rehabilitation applications, the topological analysis method of kinematic data in order to classify and anticipate the movement can be applied in different fields, like providing a safety environment, by supervising physical activities of older persons, or in virtual reality applications.

\section{References}

[1] V. Tscharne, et al., Subspace Identification and Classification of Healthy Human Gait, PLoS ONE (2013).

[2] H. Edelsbrunner, et al., Topological persistence and simplification, Discrete \& Computational Geometry (2002).

[3] P. Bendich, et al., Computing Robustness and Persistence for Images, IEEE Trans Vis Comput Graph (2010)

[4] D. Cohen-Steiner, et al., Lipschitz functions have Lp-stable persistence, Found. Comput. Math 10 (2) (2010) 127-139. 